\title{
An alternative term to make comprehensive sexuality education more acceptable in childhood
}

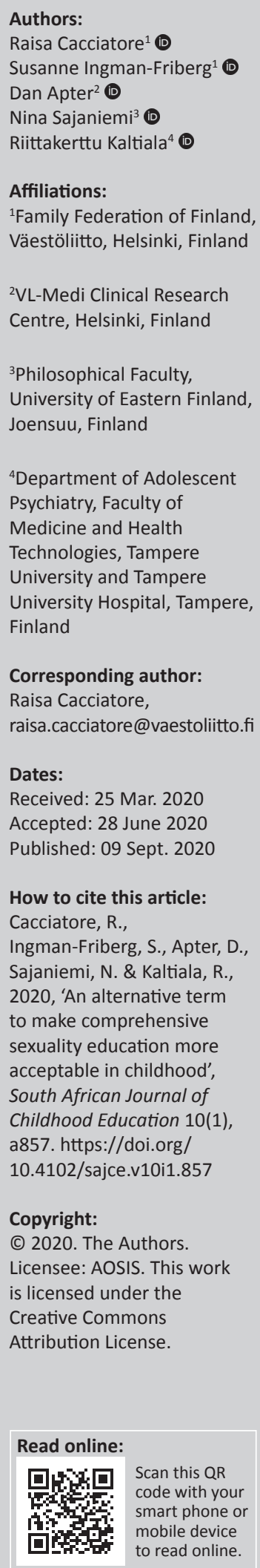

Background: Ignorance, misconceptions and fear hinder the implementation of young children's age-appropriate sexuality education (SE) globally. Methods to promote the SE of young children are needed.

Aim: We aimed to evaluate why parents and professionals resist the concept of childhood SE and to test whether a child-centred term could reduce this resistance.

Setting: We conducted nationwide studies in Finland plus focused studies in three groups.

Methods: In open online situation analysis and needs assessment studies among early childhood education professionals $(n=507)$ and parents $(n=614)$ of 1 -6-year-olds, negative, adulthood-associated connotations for the term 'sexuality education' were detected. We then evaluated whether a less sex-connected term than SE would be feasible to promote SE of young children. We combined 'body' and 'emotion', after our earlier study on children's most common sexuality-related expressions, to form the new Finnish term Kehotunnekasvatus [bodyemotion education] and tested it among professionals of sexual health $(n=17)$ and early education $(n=63)$ and primary health nurses $(n=29)$.

Results: Acceptance of the new term was excellent in all three groups; the new term was reported as 'more positive, more neutral, downplaying thoughts of sex'. Most respondents deemed it appropriate, necessary and usable in their work. Furthermore, the majority of those working daily with the parents of young children preferred the new term to 'sexuality education'.

Conclusion: After testing the functionality of a new Finnish term among Finnish professionals, the authors suggest considering replacing the term 'sexuality education' with a more child-centred and less sex-connected synonym when referring to SE for young children.

Keywords: childhood sexuality education; adultism; child sexuality; heath promotion; early childhood education and care.

\section{Introduction}

During the intense years of early development, sexual health and rights are widely overlooked (Brilleslijper-Kater \& Baartman 2000; Davies \& Robinson 2010; Morawska et al. 2015; Robinson \& Davies 2016; Stone, Ingham \& Gibbins 2013). Studies show that 1-6-year-old children are curious and learn about sexuality early from a vast array of sources, including unreliable ones. Socialisation in sexual issues not only takes place in the family, but also with kindergarten and preschool peers and staff, media and marketing and nearby older minors (Albury \& McKee 2017; Collins et al. 2017; Davies \& Robinson 2010; Hornor 2004; Josephs 2015; Larsson \& Svedin 2002). Despite this, children's right to receive reliable age-appropriate information, safety skills and positive attitudes regarding their sexuality is poorly implemented.

Opposition to sexuality education (SE) provision in schools, even to adolescents, continues strong in half the countries of Europe (Ketting et al. 2018). No countries have mandatory national SE programmes for early education, and professionals are mostly untrained in this. Hence, children do not receive planned, equal and accurate responses to their needs related to sexual development (Davies \& Robinson 2010; Robinson 2013; Sandnabba et al. 2003). International recommendations, however, support early introduced comprehensive SE, for example, the United Nation's Convention on the Rights of the Child 1989, the World Health Organisation (WHO) Regional Office for Europe and the Federal Centre for Health Education's (BZgA) Standards for Sexuality Education in Europe 2010, the World Association for Sexual Health's (WAS) Declaration of Sexual Rights 2014 and the Federation of European Ombudspersons 
for Children's Position Statement 2017. The European Court of Human Rights ruled in 2017 that children have the right to early SE, even despite parental prohibition (European Court of Human Rights 2018).

In addition, childhood sexual development and common sexual behaviours are minimally researched. Children are treated as primitive forms of adults rather than from their own perspective (LeFrancois 2013). Studies of childhood sexuality show that adult-like sex or reproduction was not the focus of young children's behaviours and questions (Brilleslijper-Kater \& Baartman 2000; Cacciatore et al. 2018; Sandnabba et al. 2003; Volbert 2000). In studying and approaching children's sexuality, the child's view should be central and respected (Flanagan 2011, 2014; Mckee et al. 2010; UN 1989). Childhood is a period of becoming familiar with one's body and feelings, building necessary socio-emotional skills, self-esteem and body image, learning norms and relationships, and seeking pleasure and safe closeness. The content of SE for young children should respond to this need (Cacciatore, Korteniemi-Poikela \& Kaltiala 2019; United Nations Educational, Scientific and Cultural Organization UNESCO, 2009; United Nations Population Fund UNFPA 2014; WHO Regional Office for Europe and BZgA 2010). In our survey study among early childhood education and care (ECEC) professionals and parents of 1-6-year-olds, the most commonly observed sexuality-related verbal expressions among children were comments on the body, and the most commonly observed sexuality-related behaviours were openly displayed emotions such as infatuation for one other (Cacciatore et al. 2020). Hence, young children's SE should provide especially knowledge, skills and positive attitudes about the body and showing emotions.

Many barriers have blocked the implementation of SE for young children, among them erroneous cultural beliefs, myths, fear and ignorance. In our clinical experience, common objections include that children are not fertile and therefore need not know about sexuality, that any information destroys childhood innocence and that SE is conducive to sexual abuse, promiscuity, sex or childbirth at an early age. 'Let them be kids!' and 'Sex and a child do not fit in the same sentence!' are adages, by which adults want to protect their children against too-early information on sex, which is what they fear SE to be. In both parents and professionals, this has caused ambivalence about childhood SE and provoked emotional argumentation, reluctance and an urge to reject the topic (Davies \& Robinson 2010; Flanagan 2011; Ketting et al. 2018). This has suppressed sensible discussions around childhood SE (Goldman 2013; Merghati-Khoei, Abolghasemi \& Smith 2014).

Misunderstandings about the content of age-matched SE may hinder its implementation. It is of utmost importance that all adults, regardless of background, education and literacy, gain knowledge of what young children's SE should be. Language creates reality. The simplicity of the concepts used is crucial. The first obstacle to understanding childhood SE may be the negative response to the term 'sexuality education'. An individual's ability to understand terminology well enough to make health-promoting decisions is often inadequate. Interventions to improve outcomes associated with health literacy are needed (Geboers et al. 2018). Therefore, alternative terminology for referring to very young children's sexuality and SE, nevertheless covering the relevant contents, may be a helpful solution.

Our aims were (1) to evaluate whether early childhood education professionals and parents of 1-6-year-olds are critical of childhood SE because of connotations of the concept SE with adulthood sexuality and (2) to test whether an alternative term for comprehensive childhood SE, Kehotunnekasvatus [Body-Emotion Education], could reduce resistance to young children's SE.

\section{Method}

The stepwise study plan is presented in Figure 1.

\section{Two online studies}

To gain an overview of the situation, obstacles and needs regarding childhood SE in Finland, we first conducted two online surveys of ECEC professionals (study A) and parents of 1-6-year-olds (study B) (Figure 1). The surveys explored adults' experiences of, thoughts on and attitudes to sexuality and SE among 1-6-year-old children.

\section{Participant selection for the online studies}

- ECEC professionals. In May 2013, via e-mail, we asked (1) the person who organises training days for ECEC professionals, (2) the person who organises the nationwide annual trade fair on ECEC and (3) municipal district managers of ECEC to forward a link to our Questionnaire A to professionals in the field (Cacciatore et al. 2020).

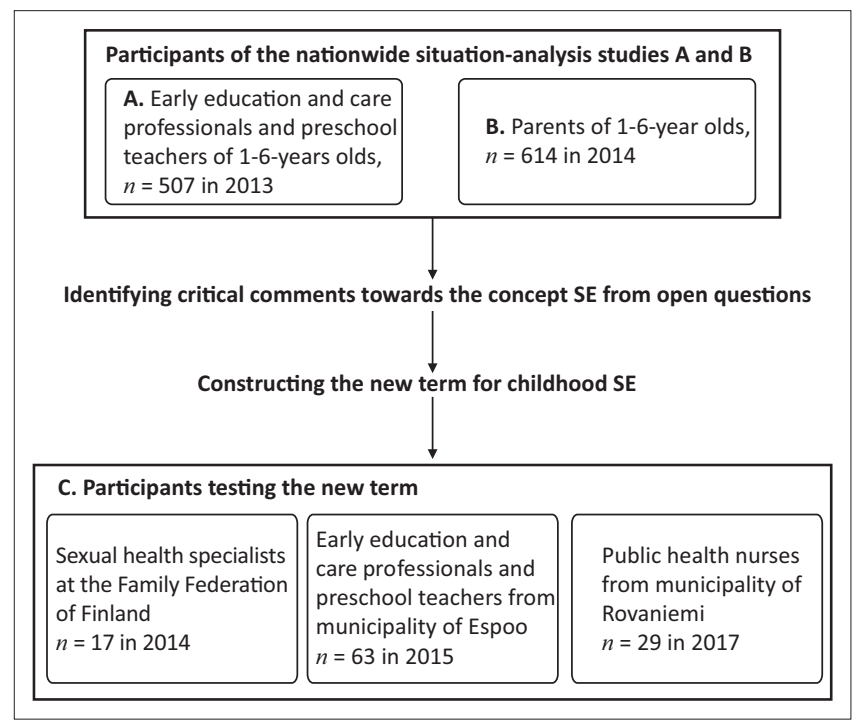

$\mathrm{SE}$, sexuality education.

FIGURE 1: Flow chart. 
- Parents. In May 2014, we invited parents of 0-6-year-olds to respond to web-based Questionnaire B through the web pages of (1) the Family Federation of Finland, (2) one baby magazine, (3) one family magazine and (4) one tabloid.

For both studies, we set the response time at two weeks. In our covering text, we stated that participation was voluntary, and all data would remain anonymous. We deemed responding to the web-based questionnaire to be informed consent. No responses were excluded because of inappropriate language. The University of Helsinki Ethical Review Board in the Humanities and Social and Behavioural Sciences approved the parents' study. We carried out the studies following the principles of the Declaration of Helsinki.

\section{Questionnaire design for online studies A and B}

Our web-based survey on adults' reflections on sexuality and SE among 1-6-year-old children was based on the comprehensive educational model in the Standards for Sexuality Education in Europe(WHO2010). The questionnaires comprised multiple-choice questions on all topics of the standards. The survey questionnaire for professionals (A) presented 91 multiple-choice statements/questions and 13 open-ended questions, and the survey questionnaire for parents (B) included 85 multiple-choice statements/ questions and 25 open-ended questions. In the open-ended questions, the respondents were asked to report their experiences of, thoughts on and attitudes to sexuality and SE among 1-6-year-old children (Appendix 1).

The first data analysed for the present study were the responses to the open-ended questions in the surveys for professionals (A) and parents (B).

\section{Participants and attrition}

The professionals' questionnaire (A) was opened 267 times without being completed and filled in 507 times, yielding a response rate of $65 \%$, whereas the questionnaire for parents was opened 1888 times without being completed and filled in 614 times, giving a response rate of $25 \%$. The same person may, however, have opened the questionnaire several times before answering. The distribution of both groups represented the population of Finland across demographic characteristics.

\section{Data analyses}

We analysed the open-ended questions in Questionnaires A and B qualitatively, first inductively and then deductively. Inductive and deductive reasoning approaches in the process of qualitative data analysis are described by Elo and Kyngäs (2008:107-115). In the inductive analysis, we conventionally read the material several times to understand the pros and cons of children's SE. Surprisingly, the term 'sexuality education' was one target of criticism: 'We do educate, but we won't call it SE'. 'In my opinion, childhood sexuality is the wrong word and gives the wrong impression'. In the deductive or directed thematic content analysis, we read the material through again, searching for comments that criticised, misunderstood or challenged more the term 'sexuality education' than the education. A presentation of this criticism appears in the 'Results' section.

\section{An alternative term for childhood sexuality education}

Secondly, we examined the possibility of replacing the Finnish term for 'sexuality education' for this age group in order to distract attention from adult-like sexuality and better reflect the content of childhood SE. We constructed a new term based on the most common topics of children's verbal expressions and behaviours related to SE themes in day care (Cacciatore et al. 2020). Over 50\% of professionals and parents had stated that children in the groups they taught or at home asked daily or weekly questions about different body parts and their functions (such as the navel, ear, 'willy'/genitals, buttocks) and hygiene (such as the appropriate way to clean the buttocks/genitals, teeth and hands). Over $50 \%$ of professionals and parents had stated that children talked daily or weekly about liking, infatuation or love for other children or familiar adults (Cacciatore et al. 2020). On the behavioural level, children were most commonly observed to express their emotions easily and to show lots of feelings of infatuation, affection and liking towards each other, for example, by 'kiss chase' games. All these related to the SE topics 'The Body' and 'Emotions' in The Standards (WHO 2010). We, therefore, decided to call young children's SE, Kehotunnekasvatus [body-emotion education], to focus on their major expressions and interests.

\section{Testing the new term}

To test the new term's acceptability and usefulness as an alternative to $\mathrm{SE}$ in the youngest age groups, we conducted surveys among three different groups of professionals. We formulated a written questionnaire $(C)$ to assess the pros and cons of the new term.

\section{Participants testing the new term}

Early childhood education and care professionals: Respondents were professionals in ECEC in southern Finland. They worked daily in kindergartens and/or preschools with 1-6-year-olds and their parents, usually without training or guidance in SE. We distributed Questionnaire C during a training day on aggression management skills. One of the researchers was present, explained the study and collected the completed questionnaires. The response rate was $95 \%(n=63)$.

Public health nurses (nurses): Respondents worked in Northern Finland and in their daily work met both young children and their parents. The nurses had some training and instruction on counselling about childhood sexuality. We distributed Questionnaire C to these nurses before a training 
day on childhood SE. Two of the researchers were present, explained the study and collected the completed questionnaires. The response rate was $90 \%(n=29)$.

Sexual health specialists (specialists): The respondents $(n=17)$ implemented SE in their work in the same non-governmental organisation, the Family Federation of Finland (Väestöliitto), where two of the researchers worked. The specialists worked as sexuality counsellors, therapists, social workers and healthcare professionals. They promoted SE or counselled mainly adolescents and adults. They often addressed sexuality in their work when people sought help for their problems. Only five of the specialists were counselling or producing material on childhood sexuality. We distributed Questionnaire C by internal mail. After one reminder, the response rate was $100 \%$.

Participation was voluntary, and all data were anonymous. We deemed responding to the anonymous questionnaire to be informed consent. No responses were excluded because of inappropriate language. We conducted the studies following the principles of the Declaration of Helsinki.

\section{Questionnaire C}

In Questionnaire C, we introduced the new term as a possible alternative to 'sexuality education' for 1-6-year-olds. The new concept would stress providing age- and developmentappropriate SE following the instructions of The Standards (WHO 2010). We also noted that what was central in this age group was becoming confident about one's own body, learning to control emotions, learning safety skills and acquiring the skills to negotiate about these.

Questionnaire C consisted of seven questions with Likert scale alternatives (Table 2): 'Do you think that the new term Kehotunnekasvatus [body-emotion education] as an alternative for use in young children's SE is appropriate, necessary, easy / difficult to use, suitable for parents, suitable for professionals, better/worse than SE, and you would/would not use it'. In all questions, responses ranged from 1 (positive to the new term; 'easy to use', 'appropriate', 'I would use', etc.) to 5 (negative to the new term; 'difficult to use', 'inappropriate', 'I would not use', etc.). In the analyses, response alternatives 1 and 2 were considered positive to the new term, and response alternatives 4 and 5 negative. In addition, there was one open item: 'You may write your thoughts here'.

\section{Data analysis}

The proportions of those positive and negative to the new concept on each question among the ECEC professionals, nurses and specialists were compared by cross-tabulations with Fisher's exact test statistics. We did statistical analysis using IBM Statistical Package for Social Sciences statistics for Windows version 25 (IBM Corp., Armonk, New York). Statistial significance was set at $p<0.05$.

Finally, the comments expressed in the open-ended question will be described.

\section{Ethical consideration}

The University of Helsinki Ethical Review Board in the Humanities and Social and Behavioural Sciences approved the parents' study (B). The authors confirm that ethical clearance was not needed/required for the studies A and $\mathrm{C}$.

\section{Results}

\section{Criticism of the terms 'childhood sexuality' and 'childhood sexuality education' in Questionnaires A and B}

In responses to Questionnaires A and B (Appendix 1), altogether 27 comments about the terms 'childhood sexuality' and 'sexuality education' were identified, and they were all critical: 9 from professionals, 18 from parents (Table 1). Such critical comments were found in response to the following questions:

- Adults' attitudes to, thoughts on and experiences of childhood sexuality

What forms of expressing themselves and games that you consider sexual have you observed among children? What type of emotional responses does childhood sexuality raise in you? What kind of sexual behaviour do you think is acceptable for a child, and what kind of behaviour requires intervention? Please also justify your answer.

TABLE 1: Types of critical comments on the terms of childhood sexuality and childhood sexuality education among early education professionals responding in online surveys (Questionnaires A and B, respectively) on childhood sexuality and childhood sexuality education.

\begin{tabular}{|c|c|c|}
\hline Type of criticism & $n$ & Example \\
\hline 1. No 'sexual tone' was observed in children's actions & 8 & $\begin{array}{l}\text { "Masturbation and "fingering" refer to sexual caressing of oneself, but for the child it is } \\
\text { not "sexual". Good instructions and terms are needed for professionals to be able to } \\
\text { provide information in the right way, even to parents'. (ECEC professional's comment) }\end{array}$ \\
\hline 2. Children's actions are natural, not 'sexual' & 7 & $\begin{array}{l}\text { 'I don't see the words young child and sexuality at all in the same context. There are } \\
\text { natural things about one's own body and also other things are natural, and we talk } \\
\text { about them always, when they arise'. (Parent) }\end{array}$ \\
\hline 3. The word 'sexuality' has inappropriate connotations with adult-like sexuality & 6 & $\begin{array}{l}\text { 'It's hard to think and talk about sexuality education, because "sexuality" as a word is } \\
\text { very adult-like and that, combined with children, gives rise to unpleasant connotations, } \\
\text { even though I know it means something completely different'. (Parent) }\end{array}$ \\
\hline 4. 'Sexuality education' is too complicated as a concept for children & 5 & $\begin{array}{l}\text { 'The concept sexuality education sounds unnecessarily official, but on the other hand } \\
\text { it conveys the importance of the subject'. (Parent) }\end{array}$ \\
\hline 5. Children already receive too much sexuality-related information & 1 & $\begin{array}{l}\text { 'We live in a world so full of sex that at first glance the whole idea of children's } \\
\text { sexuality education is terrifying'. (ECEC) }\end{array}$ \\
\hline
\end{tabular}

ECEC, early childhood education and care.

Note: Education professionals ( $n=507)$ and parents of $1-6$-year-olds $(n=614)$ responding in online surveys. 
- Adults' attitudes to, thoughts on and experiences of childhood SE

What are your thoughts on SE for young children? What are the difficult topics in SE? How do you implement childhood SE? How do you act in a situation where the child expresses sexuality? Please give examples. Is there anything else you would like to mention?

We categorised these comments in order of prevalence into five mutually exclusive groups: (1) no 'sexual tone' was observed in children's actions; (2) children's actions are natural, not 'sexual'; (3) the word 'sexuality' has inappropriate connotations with adult-like sexuality; (4) 'SE' is too complicated as a concept for children; and (5) children already receive too much sexuality-related information. Table 1 shows examples of the critical comments.

\section{Acceptance of the new term}

The alternative term for childhood SE, Kehotunnekasvatus [body-emotion education], was subsequently introduced to three groups of professionals in Questionnaire C. Acceptance

TABLE 2: The opinions of early childhood education and care professionals, nurses and specialists towards the new term 'body-emotion education'.

\begin{tabular}{|c|c|c|c|c|c|c|c|}
\hline \multirow[t]{2}{*}{ Question } & \multicolumn{2}{|c|}{ ECEC professionals } & \multicolumn{2}{|c|}{ Nurses } & \multicolumn{2}{|c|}{ Specialists } & \multirow[t]{2}{*}{$p$} \\
\hline & $n$ & $\%$ & $n$ & $\%$ & $n$ & $\%$ & \\
\hline Appropriateness & & & & & & & 0.089 \\
\hline 1 (appropriate) & 29 & 47.5 & 15 & 51.7 & 5 & 29.4 & \\
\hline 2 & 21 & 34.4 & 13 & 44.8 & 5 & 29.4 & \\
\hline 3 & 7 & 11.5 & 1 & 3.4 & 5 & 29.4 & \\
\hline 4 & 4 & 6.6 & 0 & 0.0 & 2 & 11.8 & \\
\hline 5 (inappropriate) & 0 & 0.0 & 0 & 0.0 & 0 & 0.0 & \\
\hline Necessity & & & & & & & 0.429 \\
\hline 1 (necessary) & 25 & 41.0 & 16 & 55.2 & 4 & 23.5 & \\
\hline 2 & 18 & 29.5 & 7 & 24.1 & 6 & 35.3 & \\
\hline 3 & 13 & 21.3 & 4 & 13.8 & 4 & 23.5 & \\
\hline 4 & 3 & 4.9 & 2 & 6.9 & 1 & 5.9 & \\
\hline 5 (unneeded) & 2 & 3.3 & 0 & 0.0 & 2 & 11.8 & \\
\hline Ease of use & & & & & & & $0.042 *$ \\
\hline 1 (easy) & 19 & 30.2 & 8 & 28.6 & 0 & 0.0 & \\
\hline 2 & 21 & 33.3 & 12 & 42.9 & 7 & 41.2 & \\
\hline 3 & 11 & 17.5 & 5 & 17.9 & 2 & 11.8 & \\
\hline 4 & 11 & 17.5 & 3 & 10.7 & 6 & 35.3 & \\
\hline 5 (difficult) & 1 & 1.6 & 0 & 0.0 & 2 & 11.8 & \\
\hline Suitability for parents & & & & & & & $0.012 * *$ \\
\hline 1 (suitable) & 27 & 44.3 & 15 & 51.7 & 5 & 29.4 & \\
\hline 2 & 17 & 27.9 & 12 & 41.4 & 3 & 17.6 & \\
\hline 3 & 10 & 16.4 & 2 & 6.9 & 7 & 41.2 & \\
\hline 4 & 7 & 11.5 & 0 & 0.0 & 2 & 11.8 & \\
\hline 5 (unsuitable) & 0 & 0.0 & 0 & 0.0 & 0 & 0.0 & \\
\hline Suitability for professionals & & & & & & & 0.264 \\
\hline 1 (suitable) & 37 & 58.7 & 19 & 65.5 & 7 & 41.2 & \\
\hline 2 & 17 & 27.0 & 7 & 24.1 & 5 & 29.4 & \\
\hline 3 & 2 & 3.2 & 2 & 6.9 & 2 & 23.5 & \\
\hline 4 & 6 & 9.5 & 1 & 3.4 & 1 & 5.9 & \\
\hline 5 (unsuitable) & 1 & 1.6 & 0 & 0.0 & 0 & 0.0 & \\
\hline Better than 'sexuality education' & & & & & & & 0.149 \\
\hline 1 (better) & 31 & 49.2 & 12 & 41.4 & 3 & 17.6 & \\
\hline 2 & 17 & 27.0 & 7 & 24.1 & 5 & 29.4 & \\
\hline 3 & 11 & 17.5 & 7 & 24.1 & 4 & 23.5 & \\
\hline 4 & 3 & 4.8 & 3 & 10.3 & 4 & 23.5 & \\
\hline 5 (worse) & 1 & 1.6 & 0 & 0.0 & 1 & 5.9 & \\
\hline Attitude to using & & & & & & & $0.031 * * *$ \\
\hline 1 (I would use) & 39 & 61.9 & 18 & 62.1 & 6 & 35.3 & \\
\hline 2 & 15 & 23.8 & 5 & 17.2 & 3 & 17.6 & \\
\hline 3 & 4 & 6.3 & 6 & 20.7 & 3 & 17.6 & \\
\hline 4 & 2 & 3.2 & 0 & 0.0 & 3 & 17.6 & \\
\hline 5 (I would not use) & 3 & 4.8 & 0 & 0.0 & 2 & 11.8 & \\
\hline
\end{tabular}

Note: Likert-scale response alternatives ranged from 1 to 5 .

$*$, ECEC professionals vs specialists, $p=0.010$; nurses vs specialists, $p=0.013$.

$* *$, Nurses vs specialists, $p=0.001$.

***, ECEC professionals vs specialists, $p=0.036$; nurses vs specialists, $p=0.039$. 
of the new term was excellent, as shown in Table 2. The majority of all respondents considered it appropriate $(82 \%, 97 \%$, 59\%, respectively, among ECEC professionals/ nurses/specialists), necessary $(70 \%, 79 \%, 59 \%)$ and usable in their work $(86 \%, 79 \%, 53 \%)$. Only two specialists $(12 \%)$ and $5 \%$ of ECEC professionals, but none of the nurses, reported that they could not use the term at all.

A majority of ECEC professionals (63\%) and nurses (71\%), but fewer SE specialists $(41 \%)$, considered the new term easy to use. Likewise, $76 \%$ of ECEC professionals and $65 \%$ of nurses in the field considered the new term even better than 'sexuality education', whereas of the specialists, $47 \%$ considered it better.

Eighty-six per cent of ECEC professionals, $90 \%$ of nurses and $71 \%$ of specialists considered the new term suitable for professionals' use. The suitability of the new term for use with parents caused more division of opinion: of the nurses, 93\% considered it suitable for parents to use; of the ECEC professionals, $73 \%$; but of the specialists, only $47 \%$. However, no one found the new term totally unsuitable for use with parents.

The differences between the groups were statistically significant in concepts of ease, attitude toward use and suitability for use with parents (Table 2).

To the open-ended item in Questionnaire C, we received opinions from 12 specialists and 4 ECEC professionals and 4 nurses.

Of these, some comments highlighted the benefits of the new term:

'Body-emotion education' as a concept may perhaps more clearly reflect or describe the content. I think that using it will make it easier to approach a subject which may otherwise be difficult to address.' (Nurse)

'Body-emotion education' is more neutral and downplays thoughts of sex; it is more positive and may inspire parents to think that this is important for their children ... I could, as a parent, use that. 'Ordinary' parents might need some time to learn the term.' (Specialist)

Some comments favoured 'SE':

'I think that a new term will confuse parents even more. I would explain these already familiar concepts more thoroughly.' (Specialist)

'Is there a shortcut in this matter? I think not. You just have to open up SE and sexuality concepts.' (Specialist)

Some respondents shared pros and cons:

'In the beginning, the new concept felt "stiff", but I believe that when it becomes more familiar, this may increase its "flexible use". I agree that SE concept among young children needs a new concept. Wonderful that this matter is been addressed and a new term is being developed.' (ECEC professional)

'Both are good words. SE needs more explaining.' (Nurse)
Some respondents also proposed alternative concepts in Finnish.

'Should we call the topic 'me and others?' (Specialist)

Two comments described a practical experience:

'Although child SE is clear to me, and I view it as important, parents do not. For me, child SE supports a positive self-image and underscores the importance of solid and safe intimacy. In practice, discussing child sexuality with parents always raises concerns. Parents are aware of and concerned about it because they want to protect their children from bad information. Some parents become anxious or angry. In the few moments dedicated to discussing it, more time is spent clarifying and explaining the concept of ' $\mathrm{SE}^{\prime}$ ' and calming parents' negative emotional responses than discussing what to teach children.' (Specialist)

'The theme of 'taboo' hit close to home when I started my job at the clinic. We carry out a process: a selection of themes that should be brought up at the visits. Once, a really nice 4-year-old boy came with his dad. We talked really naturally. Then I asked, 'How does he express his sexuality?' The dad froze on the spot. He tensed up. He asked what I meant by that! I tried to explain. The rest of the visit was very stiff. I thought I shouldn't have used the word 'sexuality'. That gave him a totally wrong impression! I haven't actively brought up the subject since. Only if a family brings it up first.' (Nurse)

\section{Discussion}

Sexuality education is vital for supporting children and young people in their sexual and general development. It enables them to increase their knowledge of sexual and reproductive health and rights and to develop their decisionmaking, communication and risk-reduction skills, as well as positive and responsible attitudes to sexuality and relationships (WHO 2017). The objective of the present study was to explore criticism expressed towards childhood SE, to present an alternative concept for childhood SE and to test this concept's applicability among professionals working with children and in SE. This we did in order to reduce resistance and to accelerate the implementation of young children's SE in Finland.

Our study suggested that one factor hindering childhood SE was the negative adult-sexuality connotation of the term 'sexuality education'. The term 'sexuality' was considered unsuitable when applied to 1-6-year-olds. To overcome this, we formulated and tested a new childcentred term to replace the term 'sexuality education' for use with young children, however with the same content and meaning as the age- and developmentally appropriate, comprehensive SE recommended in the WHO's Standards for Sexuality Education (2010) for young children. The new term derived directly from observations of what sexualityrelated content emerges in young children's everyday verbal expressions and behaviour, underlined the age- and developmental appropriateness of the education as opposed to teaching adult-centred sexual topics to minors (Cacciatore et al. 2020). 
The healthcare and ECEC professionals indicated acceptance of the new term. The majority of all respondents considered it necessary, appropriate, usable in their work and suitable for professionals. Moreover, the majority of ECEC professionals and nurses working daily with parents considered the new term better than SE, easy and suitable for use with parents. The new term was welcomed more positively by professionals in daily contact with parents of young children than by specialists working daily with sexual issues.

\section{Connotations of adulthood - A major obstacle}

Our online studies indicated that one factor impeding the implementation of childhood SE in Finland was the adulthood connotation of the term 'sexuality'. Our finding concurs with those of studies in Europe, New Zeland, Australia and the United States of America showing that for many adults the words 'children' and 'sexuality' are incompatible and have risky connotations (BrilleslijperKater \& Baartman 2000; Flanagan 2014; Hornor 2004; Robinson, Smith \& Davies 2017). 'Sexuality' in the standard language is associated with sex and reproduction (Flanagan 2014; Kurtuncu et al. 2015). Our findings are in line with those presented by Leander, Larsen and Munk (2018), who quoted a kindergarten director: 'When children play doctor games, they don't think of it as something sexual. The thoughts of the adults/parents make it something bad'. Adulthood-connected misunderstandings impede the promotion of SE in childhood and even negotiations about it among parents and professionals (Flanagan 2011; Kaeser, DiSalivo \& Moglia 2000; Merghati-Khoei et al. 2014). For this reason, the topic is frequently avoided and overridden in everyday life.

Taboos associated with the word 'sexuality' even impede SE for adolescents (Walker \& Milton 2006), and using less sex-loaded terms such as 'health education', 'relation education', 'life-skills education' or 'youth education' has often been necessary in order to initiate SE (Ketting et al. 2018). Sexuality education for young children is even more taboo. The time intended for guiding parents to provide appropriate SE was often wasted in explaining the term and calming abrupt responses, emphasised some respondents in our study. Parents were easily alarmed, and fear and erroneous beliefs were common, as also claimed by Robinson et al. (2017).

\section{Professionals' acceptance of the new term}

Early childhood education and care professionals and nurses expressed a marked preference for the new term over 'sexuality education'. Possibly they had experiences of obstacles to discussing childhood sexuality with parents and co-workers, who were unprepared and lacked training to understand and to negotiate about childhood sexuality and SE, under several misapprehensions and harbouring prejudices.
Nevertheless, children play sexual games and ask abundant questions in day care (Cacciatore et al. 2020; Larsson \& Svedin 2002; Sandnabba et al. 2003), where professionals need to make spontaneous decisions about what are developmentally and culturally correct and health-promoting, age-appropriate answers to infants and with a wide diversity of children (Davies, Glaser \& Kossoff 2000; Leander et al. 2018). They need tools and competencies to enhance parents' and coworkers' knowledge and acceptance of the subject and to foster children's rights and healthy development. Using simple language is one means to promote health literacy (Geboers et al. 2018).

The sexual health specialists found the new term easy to use significantly less often and expressed less commonly positive attitudes towards using it. The specialists' work was different from what the other professionals did among families with young children. They met people who were prepared to discuss sexuality-related topics. Many specialists preferred to use the term 'sexuality education' and to make it more known, as Goldman also found to be the case in Australia (2013). The specialists' viewpoint may be biased by a lack of experiences of obstacles in the field.

\section{Child-centred concepts}

Words create associations, images and emotions. Because of the sensitive nature of childhood SE, professionals may need words to explain child sexual development and behaviours to parents while avoiding harmful misunderstandings. The difference of childhood sexuality from that of adults becomes more noticeable using age-specific concepts.

Adult words lead to adult-like ideas of children's behaviour (Flanagan 2014). LeFrancois (2013) talked about adultism as adult-centric policies and practices harming children's lives. Adultism results in disadvantage and oppressive social relations. In the case of sexual health, adultism prevents children from receiving the education, information and protection they need and are entitled to (UN 1989). The ECEC professionals' perturbation, confusion and distress regarding the term 'sexuality' contributes to refusal to implement childhood SE (Merghati-Khoei et al. 2014). In a study in the United Kingdom, parents felt that they were interpreting some behaviours and questions from their 3-7-year-old children using adult sexual scripts rather than considering the context from the child's perspective (Stone et al. 2013). Flanagan (2014) noted that parents, teachers and social workers frequently named children's actions from their adult perspectives on sexuality, which led to adult constructions and judgements of childhood sexuality.

One problem impeding the promotion of childhood SE has been the lack of terms free from adulthood connotations. Child-centred frames of sexuality, created with childcentred words, may enable ECEC professionals, parents and policymakers to negotiate and plan childhood SE without serious negative prejudice. 
In some languages, words describing childhood sexuality are different from those applied to adults or adolescents. This makes it easier for parents to understand that childhood sexuality is different (Cacciatore et al. 2019). For example, the term 'masturbation' may be offensive to parents unfamiliar with the concept of sexuality in young children (Mallants \& Casteels 2008; Nechay et al. 2004). Using words such as 'selfsoothing' have been shown to be more acceptable. In fact, childhood masturbation is mostly aimed at calming (Mallants \& Casteels 2008; Sandnabba et al. 2003) as opposed to becoming excited. Unnutus is a new Finnish term to refer to childhood masturbation, introduced by the Family Federation of Finland 2000 (Cacciatore \& Korteniemi-Poikela 2000). It stems from the Finnish word for 'sleep'. To refer to a child's genitals, there are already traditional words in everyday Finnish, pimppi [girls' genitals] and pippeli [boys' genitals]. Similarly, in Swedish there are snippa and snopp, in Estonian tussu and noku. Children's genitals look different and function differently from those of adults; thus, it is natural to use different words to refer to them. Similarly, a special term can make childhood SE easier for parents to understand and accept.

Child-centred words are not euphemisms, but options and synonyms for describing childhood sexuality. Child-specific terms highlight that children have their own kinds of bodies, experiences, intentions, perspectives and needs. Using different words for children's sexuality is not a repressed, evasive or euphemistic representation, but can help adults to see the difference and to overcome their rejections, misunderstandings and objections.

\section{The implementation of the new term in Finland}

The Family Federation of Finland has introduced the new term, 'body-emotion education', on its Child and Sexuality webpages, in materials, training sessions and in the media since 2015. At the end of 2019, a Google search yielded over 30000 hits.

In October 2016, the new National Core Curriculum for Early Childhood Education and Care was delivered, which for the first time was an official and binding document based on the legislation (Finnish National Agency for Education 2018). Each municipality was required to draw up local curricular and qualification requirements based on the national document, to outline how the objectives are to be achieved. In 2017, the Family Federation of Finland encouraged all municipalities to implement SE in their local curricula, at the same time introducing the new term. As a result, at least 21 municipalities out of the 311 in Finland included SE as a part of their mandatory local curricula - 18 using the new term alone or together with SE. These municipalities cover $37 \%$ of Finnish 0-6-year-olds.

Two Finnish Members of Parliament tabled a written question to the Speaker of Parliament on body-emotion education and the prevention of sexual harassment starting in early childhood education in December 2017.

\section{Limitations and strengths}

A limitation of the online studies is that we do not know how widely the links to Questionnaires A and B were distributed. We know how many times the link was opened, but we do not how many individuals received the link without opening it. Individuals uncomfortable with sexuality issues may have avoided the study, resulting in a bias towards respondents willing to communicate about sexuality.

The results in testing the new term are preliminary as the respondent groups were small, and we tested a new Finnish term among Finnish professionals. The new term may not be directly transferable to other languages.

The new term, Kehotunnekasvatus, was built on extensive research among ECEC and parents.

\section{Conclusion}

Our study showed that simple, quick and creative methods such as finding new and less adulthood-connected terms can be introduced to overcome resistance towards childhood SE. Healthcare and education professionals welcomed the new term, especially those working daily with parents of young children.

Parents and teachers of young children need support and information to understand the content and importance of comprehensive age-appropriate SE for young children. Nearby adults' ability and capacity to provide SE is crucial for children's safety and well-being. Promoting health literacy uses methods such as reformulating health information to make it better understood.

Policymakers, educational and health authorities, and specialists must make agreements to offer young children accurate SE. New, developmentally appropriate terms can facilitate these negotiations.

More studies are needed to identify the obstacles to childhood SE in different countries. In terminology, idiomatic expressions may be needed for different languages.

\section{Acknowledgements}

Part of this study was presented at the EURAPAG 2017, 14th European Congress of Paediatric and Adolescent Gynaecology. 7th-10th June 2017, Vilnius, Lithuania. Cacciatore, R., Ingman-Friberg, S., Apter, D. \& Sajaniemi, N., 'Can alternative words for describing childhood sexuality education reduce common resistance?'

\section{Competing interests}

The authors declare that they have no financial or personal relationships that may have inappropriately influenced them in writing this article. 


\section{Authors' contributions}

The research was performed by R.C. and was supervised by S.I.-F., D.A., N.S. and R.K. All authors contributed to the writing of this article.

\section{Funding information}

This work was partially supported by the Finnish Cultural Foundation (170158).

\section{Data availability statement}

Original data set available from the first author by request.

\section{Disclaimer}

The views and opinions expressed in this article are those of the authors and do not necessarily reflect the official policy or position of any affiliated agency of the authors.

\section{References}

Albury, K. \& Mckee, A., 2017, 'Sexual cultures, entertainment media, and communications technologies', in L. Allen \& M.L. Rasmussen (eds.), The palgrave handbook of sexuality education, pp. 415-421, Palgrave Macmillan, London.

Brilleslijper-Kater, S.N. \& Baartman, H.E.M., 2000, 'What do young children know about sex? Research on the sexual knowledge of children between the ages of 2 and 6 years', Child Abuse Review 9(3), 166-182. https://doi.org/10.1002/1099. 0852(200005/06)9:3\%3C166::AID-CAR588\%3E3.0.CO;2-3

Cacciatore, R.S.-M., Ingman-Friberg, S.M.-L., Lainiala, L.P. \& Apter, D.L., 2020, 'Verbal and Behavioral Expressions of Child Sexuality Among 1-6-Year-Olds as Observed by Daycare Professionals in Finland', Archives of Sexual Behavior. https://doi. org/10.1007/s10508-020-01694-y

Cacciatore, R. \& Korteniemi-Poikela, E., 2000, Vauvasta naperoiseksi - pienten lasten seksuaaliterveydestä. Opas 0-6 -vuotiaiden seksuaalisesta kehityksestä ja sen seksuaaliterveydesta. Opas
tukemisesta [From baby to toddler - About the sexual health of young children. A guide to support the sexual development of 0-6-year olds], VL-Markkinointi, Helsinki.

Cacciatore, R., Korteniemi-Poikela, E. \& Kaltiala, R., 2019, 'The steps of sexuality - A developmental, emotion-focused, child-centered model of sexual development and sexuality education from birth to adulthood', International Journal of Sexual Health 31(3), 319-338. https://doi.org/10.1080/19317611.2019.1645783

Collins, R.L., Strasburger, V.C., Brown, J.D., Donnerstein, E., Lenhart, A. \& Ward, L.M., 2017, 'Sexual media and childhood well-being and health', Pediatrics 140(2), 162-166. https://doi.org/10.1542/peds.2016-1758X

Davies, C. \& Robinson, K., 2010, 'Hatching babies and stork deliveries: Risk and regulation in the construction of children's sexual knowledge', Contemporary Issues in Early Childhood 11(3), 249-262. https://doi.org/10.2304/ciec.2010.11.3.249

Davies, S.L., Glaser, D. \& Kossoff, R., 2000, 'Children's sexual play and behavior in pre school settings: Staff's perceptions, reports, and responses', Child Abuse and Neglect 24(10), 1329-1343. https://doi.org/10.1016/S0145-2134(00)00184-8

Elo, S. \& Kyngäs, H., 2008, 'The qualitative content analysis process', Journal of Advanced Nursing 62(1), 107-115. https://doi.org/10.1111/j.1365-2648.2007.04569.x

European Court of Human Rights, 2018, Sex education in state schools, children's rights, viewed 25 January 2020, from https://www.echr.coe.int/Documents/FS Childrens_ENG.pdf.

Finnish National Agency for Education, 2018, National core curriculum for early childhood education and care, viewed 25 January 2020 , from https://www.oph.fi/ en/education-and-qualifications/national-core-curriculum-ecec-nutshell.

Flanagan, P., 2011, 'Making sense of children's sexuality: Understanding sexual development and activity in education contexts', Waikato Journal of Education 16(3), 69-79. https://doi.org/10.15663/wje.v16i3.36

Flanagan, P., 2014, 'Unpacking ideas of sexuality in childhood: What do primary teachers and parents say?', Open Review of Educational Research 1(1), 160-170. https://doi.org/10.1080/23265507.2014.972436

Geboers, B., Reijneveld, S.A., Koot, J.A.R. \& De Winter, A.F., 2018, 'Moving towards a comprehensive approach for health literacy interventions: The development of a health literacy intervention model', International Journal of Environmental Research and Public Health 15(1268), 16-26. https://doi.org/10.3390/ijerph15061268

Goldman, J.D.G., 2013, 'International guidelines on sexuality education and their relevance to a contemporary curriculum for children aged 5-8 years', Educational Review 65(4), 447-466. https://doi.org/10.1080/00131911.2012.714355

Hornor, G., 2004, 'Sexual behavior in children: Normal or not?', Journal of Pediatric Health Care 18(2), 57-64. https://doi.org/10.1016/S0891-5245(03)00154-8
Josephs, L., 2015, 'How children learn about sex: A cross-species and cross-cultural analysis', Archives of Sexual Behavior 44(4), 1059-1069. https://doi.org/10.1007/ s10508-015-0498-0

Kaeser, F., DiSalvo, C. \& Moglia, R., 2000, 'Sexual behaviors of young children that occur in schools', Journal of Sex Education and Therapy 25(4), 277-285. https:// doi.org/10.1080/01614576.2000.11074361

Ketting, E., Brockschmidt, L., Renner, I., Luyckfasseel, L. \& Ivanova, O., 2018, 'Sexuality education in Europe and Central Asia: Recent developments and current status', in R.A. Benavides-Torres, D.J. Onofre-Rodrigues, M.A. Marquez-Vega \& R.C. BarbosaMartinez (eds.), Sex education, pp. 75-120, Nova Science Publishers, Hauppauge, New York, NY

Kurtuncu, M., Akhan, L.U., Tanir, I.M. \& Yildiz, H., 2015, 'The sexual development and education of preschool children: Knowledge and opinions from doctors and nurses', Sexuality and Disability 33(2), 207-221. https://doi.org/10.1007/s11195-015-9393-9

Larsson, I.B. \& Svedin, C.G., 2002, 'Teachers' and parents' reports on 3- to 6-year-old children's sexual behavior - A comparison', Child Abuse and Neglect 26(3), 247-266. https://doi.org/10.1016/S0145-2134(01)00323-4

Leander, E.M.B., Larsen, P.L. \& Munk, K.P., 2018, 'Children's doctor games and nudity at danish childcare institutions', Archives of Sexual Behavior 47(4), 863-875. https://doi.org/10.1007/s10508-017-1144-9

LeFrancois, B.A., 2013, 'Adultism', in T.S. Teo (ed.), Encyclopedia of critical psychology: Springer reference, pp. 1-4, Springer-Verlag, Berlin

Mallants, C. \& Casteels, K., 2008, 'Practical approach to childhood masturbation - A review', European Journal of Pediatrics 167(10), 1111-1117. https://doi. org/10.1007/s00431-008-0766-2

McKee, A., Albury, K., Dunne, M., Grieshaber, S., Hartley, J., Lumby, C. et al., 2010 'Healthy sexual development: A multidisciplinary framework for research', 'Healthy sexual development: A multidisciplinary framework for research',
International Journal of Sexual Health 22(1), 14-19. https://doi.org/ International Journal of Sex

Merghati-Khoei, E., Abolghasemi, N. \& Smith, T.G., 2014, “"Children are sexually innocent": Iranian parents' understanding of children's sexuality', Archives of Sexual Behavior 43(3), 587-595. https://doi.org/10.1007/s10508-013-0218-6

Morawska, A., Walsh, A., Grabski, M. \& Fletcher, R., 2015, 'Parental confidence and preferences for communicating with their child about sexuality', Sex Education 15(3), 235-248. https://doi.org/10.1080/14681811.2014.996213

Nechay, A., Ross, L.M., Stephenson, J.B.P. \& O’Regan, M., 2004, 'Gratification disorder ("infantile masturbation"): A review', Archives of Disease in Childhood 89(3), 225-226. https://doi.org/10.1136/adc.2003.032102

Robinson, K.H., 2013, 'Children's sexual subjectivities', in K.H. Robinson (ed.), Innocence, knowledge and the construction of childhood, pp. 87-110, Routledge, New York, NY.

Robinson, K.H. \& Davies, C., 2016, 'Sexuality education in early childhood', in L. Allen \& M.L. Rasmussen (eds.), The palgrave handbook of sexuality education, pp. 217-242, Palgrave Macmillan, London.

Robinson, K.H., Smith, E. \& Davies, C., 2017, 'Responsibilities, tensions and ways forward: Parents' perspectives on children's sexuality education', Sex Education 17(3), 333-347. https://doi.org/10.1080/14681811.2017.1301904

Sandnabba, N.K., Santtila, P., Wannäs, M. \& Krook, K., 2003, 'Age and gender specific sexual behaviors in children', Child Abuse \& Neglect 27(6), 579-605. https://doi. org/10.1016/S0145-2134(03)00102-9

Stone, N., Ingham, R. \& Gibbins, K., 2013, “"Where do babies come from?” Barriers to early sexuality communication between parents and young children', Sex to early sexuality communication between parents and young children',
Education 13(2), 228-240. https://doi.org/10.1080/14681811.2012.737776

United Nations (UN), 1989, Convention on the right of the child, viewed 25 January 2020, from http://legal.un.org/avl/ha/crc/crc.html.

United Nations Educational, Scientific and Cultural Organization and United Nations Population Fund (UNESCO), 2009, International technical guidance on sexuality education - An evidence-informed approach for schools, teachers and health educators', The rationale for sexuality education, viewed 25 January 2020, from https://unesdoc.unesco.org/ark:/48223/pf0000183281.

United Nations Population Fund (UNFPA), 2014, UNFPA Operational guidance for comprehensive sexuality education: A focus on human rights and gender, viewed 25 January 2020, from https://www.unfpa.org/sites/default/files/pub-pdf/UNFPA\%20 Operational\%20Guidance $\% 20$ for $\% 20$ CSE $\% 20$-Final $\% 20$ WEB $\% 20$ Version.pdf.

Volbert, R., 2000, 'Sexual knowledge of preschool children', Journal of Psychology \& Human Sexuality 12(1-2), 5-26. https://doi.org/10.1300/J056v12n0102

Walker, J. \& Milton, J., 2006, 'Teachers' and parents' roles in the sexuality education of primary school children: A comparison of experiences in Leeds, UK and in Sydney, Australia', Sex Education 6(4), 415-428. https://doi.org/10.1080/ 14681810600982267

World Association for Sexual Health (WAS), 2014, Declaration of sexual rights, viewed 25 January 2020, from https://worldsexualhealth.net/wp-content/ uploads/2013/08/declaration_of_sexual_rights_sep03_2014.pdf.

World Health Organisation (WHO) Regional Office for Europe and the Federal Centre for Health Education (BZgA), 2010, Standards for sexuality education in Europe, a framework for policy makers, educational and health authorities and specialists, viewed 25 January 2020, from https://www.bzga-whocc.de/fileadmin/user_ upload/WHO_BZgA_Standards_English.pdf.

World Health Organization (WHO) Regional Office for Europe and the Federal Centre for Health Education (BZgA), 2017, Training matters: A framework for core competencies of sexuality educators, viewed 31 July 2020, from https://www. bzga-whocc.de/fileadmin/user_upload/BZgA_Training_matters_EN.pdf. 


\section{Appendix 1}

TABLE 1-A1: All open-ended questions in studies A and B.

What are your thoughts on sexuality education for small children? (A, B)

What type of emotional responses does childhood sexuality raise in you? $(A, B)$

What forms of expressing themselves and games that you consider sexual have you observed among children? (A, B)

How do you implement childhood sexuality education in your work/in your role as the grown-up of the family? (A, B)

How do you act in a situation where the child expresses sexuality? Please give examples. (A, B)

Have you observed any behaviour of a child that may be due to some negative sexuality-related experience of the child? Please describe. (A, B)

What kind of sexual behaviour do you think is allowed for a child and what type of behaviour should be intervened with? Please also justify your answer. (A, B)

What other topics related to children's sexuality did you miss in your training? (A)

On what other topics would you like to get additional material for childhood sexuality education? (A)

What do you think about if the gender of a child is concealed from the child and the environment before school age? Have you any experiences with this? (A)

According to your experiences, are children allowed to play gender-typical games as well as games typical for the opposite gender (e.g. the boys may play both pirate games and princess games)? (A)

How is sexuality education provided in homes? Do parents have enough knowledge and skills to provide age-appropriate sexuality education? (A)

In your opinion, how is sexuality education provided in early childhood education and care? Do you think professionals have enough knowledge and skills to implement age-appropriate sexuality education? (B)

What are the difficult topics in sexuality education? (B)

Have you received support and helpful information from a child welfare clinic about children's sexuality education? Please give examples. (B)

How was sexuality education provided at your childhood home? Please give examples. (B)

If you wish, express what word you use for the boy's and the girl's genitals. (B)

Have you any knowledge or training on how to provide sexuality education for young children? Please indicate what. (B)

Is there anything else you would like to mention? $(A, B)$

$\mathrm{A}=$ early childhood education and care professionals $(n=507)$; B = parents of 1-6-year-olds $(n=614)$ 